\title{
Expressions of miR-15a and its target gene HSPA1B in the spermatozoa of patients with varicocele
}

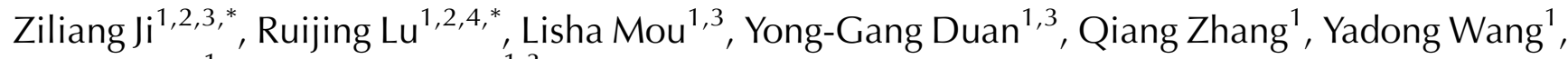 \\ Yaoting Gui ${ }^{1}$ and Zhiming Cai ${ }^{1,3}$ \\ ${ }^{1}$ Guangdong and Shenzhen Key Laboratory of Male Reproductive Medicine and Genetics, Institute of Urology, \\ Shenzhen PKU-HKUST Medical Center, Peking University Shenzhen Hospital, Shenzhen 518036, China, \\ ${ }^{2}$ Shantou University Medical College, Shantou 515041, China, ${ }^{3}$ Centre of Reproductive Medicine and Andrology, \\ Shenzhen Second People's Hospital, First Affiliated Hospital of Shenzhen University, Shenzhen 518035, China and \\ ${ }^{4}$ Department of Clinical Laboratory, Peking University Shenzhen Hospital, Shenzhen 518036, China
}

Correspondence should be addressed to Z Cai; Email: caizhiming2000@163.com or to Y Gui; Email: guiyaoting2007@aliyun.com

*(Z Ji and R Lu contributed equally to this work)

\begin{abstract}
Hyperthermia and oxidative stresses are the two central elements contributing to varicocele-related sperm damage. Growing evidence indicates that microRNAs (miRNAs) are involved in the regulation of the heat and oxidative stress responses. In this study, we analyzed the expressions of several stress-related miRNAs in the sperm and found that the expression of miR-15a was significantly decreased in patients with varicocele compared with the control. Furthermore, miR-15a repressed the expression of HSPA1B, which is a typical stressinduced chaperone protein, through directly binding its $3^{\prime}$-UTR. The expressions of miR-15a and HSPA1B exhibited an inverse correlation in sperm. Our results provide a valuable insight into the varicocele-related sperm impairment and male infertility, and may help to develop potential therapeutic targets and novel biomarkers for male infertility.

Reproduction (2014) 147 693-701
\end{abstract}

\section{Introduction}

Varicocele is characterized by abnormal dilated, elongated, and tortuous veins in the pampiniform plexus with a reflux of blood. Approximately, 15\% of general population has a varicocele, with $40 \%$ of them having fertility disorders (Will et al. 2011). Varicocele is common in infertile men and therefore it has been considered as one of the most important factors of male infertility. It can lead to testicular and epididymal malfunction, impaired spermatogenesis, and decreased semen quality. The etiology and pathophysiology of varicocele seem complicated and multifactorial (Fretz \& Sandlow 2002, Will et al. 2011). Numerous hypothetical mechanisms have been put forward, such as increased temperature in scrotum, oxidative stress, altered blood flow, hormone disturbance, and back flow of gonadotoxic metabolites (Naughton et al. 2001, Will et al. 2011).

It appears that heat and oxidative stresses are the two central elements contributing to infertility in men with varicocele (Naughton et al. 2001, Fretz \& Sandlow 2002, Ferlin et al. 2010, Will et al. 2011). More than $1{ }^{\circ} \mathrm{C}$ temperature elevation and increased reactive oxygen species (ROS) production in the testis are reported in men with varicocele (Goldstein \& Eid 1989, Mostafa et al. 2009). A growing body of literature demonstrates that increased testicular temperature and ROS can reduce sperm quality (Smith et al. 2006, Jung \& Schuppe 2007, Hamada et al. 2012). Testicular hyperthermiainduced oxidative stress builds up of ROS and can cause impaired sperm function through the oxidation of fatty acids in spermatozoa membranes or through direct damage of sperm DNA (Twigg et al. 1998). However, the underlying molecular mechanisms of varicocele-associated male infertility are not fully understood.

MicroRNAs (miRNAs) are noncoding, endogenous, small RNAs that regulate gene expression by binding to the 3'-UTR of target mRNA. By either degrading mRNA or translational repression, miRNAs regulate a variety of developmental and physiological processes including cellular differentiation, proliferation, and apoptosis (Landgraf et al. 2007, Inui et al. 2010). Numerous miRNAs are exclusively or preferentially expressed in the mouse testis (Ro et al. 2007). DICER1 is a cytoplasmic RNase III endonuclease that is essential for miRNA biogenesis as it cleaves the precursor miRNAs to 
produce mature miRNAs (Inui et al. 2010). Loss of Dicer1 in mouse postnatal male germ cells leads to infertility due to disruptions in the meiotic and postmeiotic stages (Korhonen et al. 2011, Romero et al. 2011, Greenlee et al. 2012), suggesting that miRNAs play important roles in spermatogenesis. Moreover, altered miRNAs expressions of the ejaculated spermatozoa in patients with different spermatogenic impairments have been demonstrated by microarray (Lian et al. 2009, Abu-Halima et al. 2013). But little is known about the molecular role of miRNAs in male infertility, especially in varicocele-related male infertility.

Recently, emerging data suggest that miRNAs could help to restore homeostasis upon cellular stresses. The miRNAs-mediated stress responses play important roles in plenty of human diseases, such as infection, cardiovascular disease, and cancer (Leung \& Sharp 2010, Mendell \& Olson 2012). Previous studies have shown that miR-15a, miR-16, miR-18, miR-192, and miR-320 are involved in hyperthermia or oxidative cellular stresses (Li et al. 2009, Ren et al. 2009, Wilmink et al. 2010). However, the roles of miRNAs on varicocele-related stress environment remain unclear. In this study, we examined the expressions of stress-related miRNAs in the ejaculated spermatozoa of patients with varicocele and tried to understand the molecular mechanisms of the miRNAs-mediated stress in varicocele.

\section{Materials and methods}

\section{Subjects}

The study groups consisted of 58 patients with Grade II or III varicocele and 24 healthy donors with normal semen quality and without varicocele recruited consecutively at the Peking University Shenzhen Hospital. Exclusion criteria were seminal infection, cryptorchidism, orchitis, or testicular atrophy. Varicocele was graded according to international clinical classification guidelines: Grade I, no visible or palpable distension except when the man performs the Valsalva maneuver; Grade II, palpable but not visible; and Grade III, easily visible through the scrotal skin (Will et al. 2011). Fresh ejaculate samples were collected from the patients and donors presenting to the andrology unit for routine semen analysis after given informed consent. Normal sperm parameters were defined according to World Health Organization (2010) criteria. The study was approved by the Local Ethics Committee. Written consent was obtained from the patients in the study.

\section{Semen samples}

Semen samples were collected by masturbation after 3-7 days of sexual abstinence. The samples were allowed to liquefy at $37^{\circ} \mathrm{C}$ for $30 \mathrm{~min}$ before standard semen analysis was performed according to World Health Organization (2010) criteria for sperm concentration, motility, morphology, and vitality. Semen samples were subjected to a Percoll (GE Healthcare, Uppsala, Sweden) density-gradient centrifugation to recover sperm for subsequent RNA extraction. Briefly, $1 \mathrm{ml}$ of semen was layered on discontinuous two-layer (40 and $80 \%$ ) Percoll gradients in $15 \mathrm{ml}$ conical tubes and centrifuged at $800 \mathrm{~g}$ for $30 \mathrm{~min}$. The medium used to dilute the Percoll was PBS. Spermatozoa collected from the bottom layer were washed three times in PBS and immediately frozen in liquid nitrogen until RNA extraction.

\section{RNA extraction, $R T$, and quantitative real-time PCR}

Total RNA was extracted from the sperm pellets using the miRNeasy Mini Kit (Qiagen). The quantity and quality of RNA were measured using a Nano-Drop Spectrophotometer.

RT reaction was carried out by All-in-One miRNA FirstStrand cDNA Synthesis Kit (GeneCopoiea, Inc., Rockville, MD, USA) for miRNAs and by RevertAid First Strand cDNA Synthesis Kit (Fermentas, Vilnius, Lithuania) for mRNA. Generally, $50 \mathrm{ng}$ total RNA was used for RT reaction.

The quantitative real-time PCR (qRT-PCR) for miRNAs was performed using the All-in-One miRNA qRT-PCR Detection Kit (GeneCopoiea, Inc.). Amplification reactions were performed in a $20 \mu \mathrm{l}$ final volume and were done for $40 \mathrm{cycles}\left(15 \mathrm{~s}\right.$ at $95^{\circ} \mathrm{C}, 20 \mathrm{~s}$ at $60{ }^{\circ} \mathrm{C}$, and 30 s at $70{ }^{\circ} \mathrm{C}$ ). $U 6$ small nuclear RNA was selected as the endogenous control. Primers of miRNAs were obtained from GeneCopoiea, Inc. The expressions of mRNAs were quantified by qRT-PCR using the SYBR Premix Ex Taq (Takara, Shiga, Japan). Amplification reactions were performed in a $20 \mu$ final volume and were done for 40 cycles $\left(15 \mathrm{~s}\right.$ at $95^{\circ} \mathrm{C}, 20 \mathrm{~s}$ at $55^{\circ} \mathrm{C}$, and $30 \mathrm{~s}$ at $70^{\circ} \mathrm{C}$ ). The following primers were used in this study: HSPA $1 B$ (sense, $5^{\prime}$-TGGACTGTTGGGACTCAAGGAC-3' and antisense, $5^{\prime}$-GGAACGAAACACCCTTACAGTATCA-3'), RAD51C (sense, $5^{\prime}$-CCTGTCTCTTCGTACTCGGTT- $3^{\prime}$ and antisense, $5^{\prime}$-TCCCAATGAAAGATTAGCCGTA-3'), TIA1 (sense, $5^{\prime}$-CATTTGTTCGGTT CAATTCCC- $3^{\prime}$ and antisense, $5^{\prime}$-GTTGTGCATTTCCATAC CACT-3'), JUN (sense, 5'-CGCAGCCCAAACTAACCTC-3' and antisense, $5^{\prime}$-GTAGCCATAAGGTCCGCTCT-3'), and HSP9OB1 (sense, 5'-ATTAATCCCAGACACCCGCTGA-3' and antisense, $5^{\prime}$-ATACCCTGACCGAAGCGTTG-3'). To normalize the amount of expressed mRNAs, the internal housekeeping gene GAPDH (sense, 5'-AGAAGGCTGGGGCTCATTTG-3' and antisense, 5'-AGGGGCCATCCACAGTCTTC-3') was used. Comparative $C T$ method for relative quantification was used to calculate data, which describes the expressions of the target gene in the tested samples relative to a calibrator sample from the control group and provides accurate comparison among each sample.

\section{Cell culture and transfection}

HEK 293T cell lines were cultured in DMEM supplemented with $10 \%$ fetal bovine serum, $1 \%$ penicillin, and streptomycin in $5 \%$ $\mathrm{CO}_{2}$ at $37^{\circ} \mathrm{C}$. The cells were transfected with the indicated amounts of miR-15a mimics, inhibitor, or a negative control (RIBOBIO, Guangzhou, Guangdong, China) using Lipofectamine 2000 (Invitrogen) according to the manufacturer's instructions.

\section{Western blot}

The cells were lysed in RIPA buffer (Sigma-Aldrich) supplemented with Protease Inhibitor Cocktail I (Millipore, Billerica, 
MA, USA). Protein concentration was measured using the BCA Protein Assay Kit (Pierce, Rockford, MA, USA). The cells lysates $(20 \mu \mathrm{g})$ were electrophoresed on $10 \%$ polyacrylamide gels and then transferred to PVDF membrane (Millipore). The membranes were blocked with 5\% skimmed milk and then incubated with the primary antibodies, followed by antimouse or anti-rabbit IgG HRP-conjugated secondary antibodies (Santa Cruz Biotechnology), and were visualized with Immobilon Western (Millipore). The abundance of reaction bands was determined using the Quantity One Software (Bio-Rad, Hercules, CA, USA). The intensity of the test proteins was normalized to that of $\beta$-actin, which was used as an internal control. The primary antibodies used were anti-HSPA1 antibody and anti- $\beta$-actin (Santa Cruz Biotechnology) antibody.

\section{Luciferase reporter assay}

For the production of a reporter construct, a 360-nucleotidelong $3^{\prime}$-UTR of human HSPA1B was amplified using the primers: sense, 5'-CCGCTCGAGGGGCCTTTGTTCTTTAGTA-3' and antisense, 5' ${ }^{\prime}$-ATTTGCGGCCGCTTTCATATTTAAATAAACAAATTA-3'. The PCR fragment was digested with Xhol and Notl and then cloned into psiCHECK-2 luciferase vector (Promega). As for WT, two short fragments of HSPA1B $3^{\prime}$-UTR which contains the potential binding sites for miR-15a were chemically synthesized. Then, we manually changed the potential binding sites by exchanging the $\mathrm{G}$ and $\mathrm{T}, \mathrm{A}$ and $\mathrm{C}$ as the mutant type. These four short fragments were all cloned into psiCHECKTM-2 luciferase vector respectively. The constructs were verified by sequencing. Then the luciferase reporter constructs, together with miR-15a mimics or a negative control, were transfected into HEK 293T cells. Luciferase activity at $48 \mathrm{~h}$ after transfection was detected using the dual luciferase assay system (Promega) according to the manufacturer's instructions. The Renilla luciferase activity was normalized to the firefly luciferase activity. The experiments were performed in duplicate and repeated at least three times.

\section{Statistical analysis}

Statistical significance was determined using Student's $t$-test or Mann-Whitney rank sum test, depending on whether the data was accepted by normal distribution with KolmogorovSmirnov test. Spearman's correlation was used to measure the association between miR-15a and HSPA1B. P<0.05 was considered statistically significant.

\section{Results}

\section{Semen analysis}

Table 1 shows the baseline sperm characteristics of varicocele group and control group. No differences were noted in the mean age, volume, or $\mathrm{pH}$ between the two groups. However, the sperm count, motility, and vitality of varicocele group were significantly decreased compared with the control, indicating that patients
Table 1 Patients and semen characteristics.

\begin{tabular}{lccc}
\hline Characteristics & CN $(n=24)$ & VC $(n=58)$ & $P$ value* \\
\hline Age (years) & $30.08 \pm 3.69$ & $28.81 \pm 5.94$ & 0.081 \\
Volume $(\mathrm{ml})$ & $3.05 \pm 0.89$ & $3.20 \pm 1.43$ & 0.841 \\
$\mathrm{pH}$ & $7.38 \pm 0.20$ & $7.38 \pm 0.21$ & 0.959 \\
Count $\left(10^{6} / \mathrm{ml}\right)$ & $131.77 \pm 76.49$ & $68.81 \pm 56.34$ & 0.001 \\
Percentage of motility & $61.77 \pm 9.65$ & $35.67 \pm 20.50$ & 0.001 \\
$\quad$ (grades a + b)* & & & \\
Percentage of vitality & $80.53 \pm 8.28$ & $50.69 \pm 22.45$ & 0.001 \\
\hline
\end{tabular}

$\mathrm{CN}$, control group; $\mathrm{VC}$, varicocele group. ${ }^{*} P$ value was calculated using Student's $t$-test.

with varicocele have impaired spermatogenesis and poor semen quality. The spermatozoa were then purified by centrifugation through discontinuous density gradient for RNA extraction and qRT-PCR.

\section{Expressions of stress-related miRNAs in the ejaculated spermatozoa}

As hyperthermia and oxidative stresses are the two major mechanisms for the varicocele-related spermatogenesis damage, we first selected five miRNAs (namely miR-15a, miR-16, miR-18a, miR-192, and miR-320) which were reported to be implicated in hyperthermia or oxidative cellular stresses ( $\mathrm{Li}$ et al. 2009, Ren et al. 2009, Wilmink et al. 2010). The expressions of these miRNAs in the ejaculated spermatozoa of ten pairs of patients with varicocele and the healthy donors were investigated by qRT-PCR. The results showed no significant difference in the expressions of miR-16, miR-18a, miR-192, or miR-320. However, the expression of miR-15a in the ejaculated sperm revealed significant decrease in patients with varicocele compared with healthy donors (Fig. 1A). The downregulation of miR-15a in varicocele was further verified in larger study group (Fig. 1B). Therefore, we focused on miR-15a in the following study.

\section{Regulation of HSPA1B by miR-15a}

Previous study has identified numerous target genes of miR-15a by microarray (Calin et al. 2008). Among these genes, we selected five targets reported to be involved in hyperthermia or oxidative cellular stress pathways, namely HSPA1B, HSP9OB1, RAD51C, TIA1, and JUN (Maki et al. 1990, Kyriakis et al. 1994, Kedersha et al. 2000, Qian et al. 2006, Sage et al. 2010). Moreover, all of these five genes have the putative binding sites of miR$15 \mathrm{a}$ on the $3^{\prime}$-UTR. After miR-15a mimics or inhibitor transfection in human HEK 293T cells, qRT-PCR and western blot were carried out. As shown in Fig. 2A and B, only the expression of $H S P A 1 B$ was significantly decreased when transfected with miR-15a mimics, and was significantly increased when transfected with miR$15 \mathrm{a}$ inhibitor. These results showed that the expression of HSPA1B was regulated by miR-15a. 

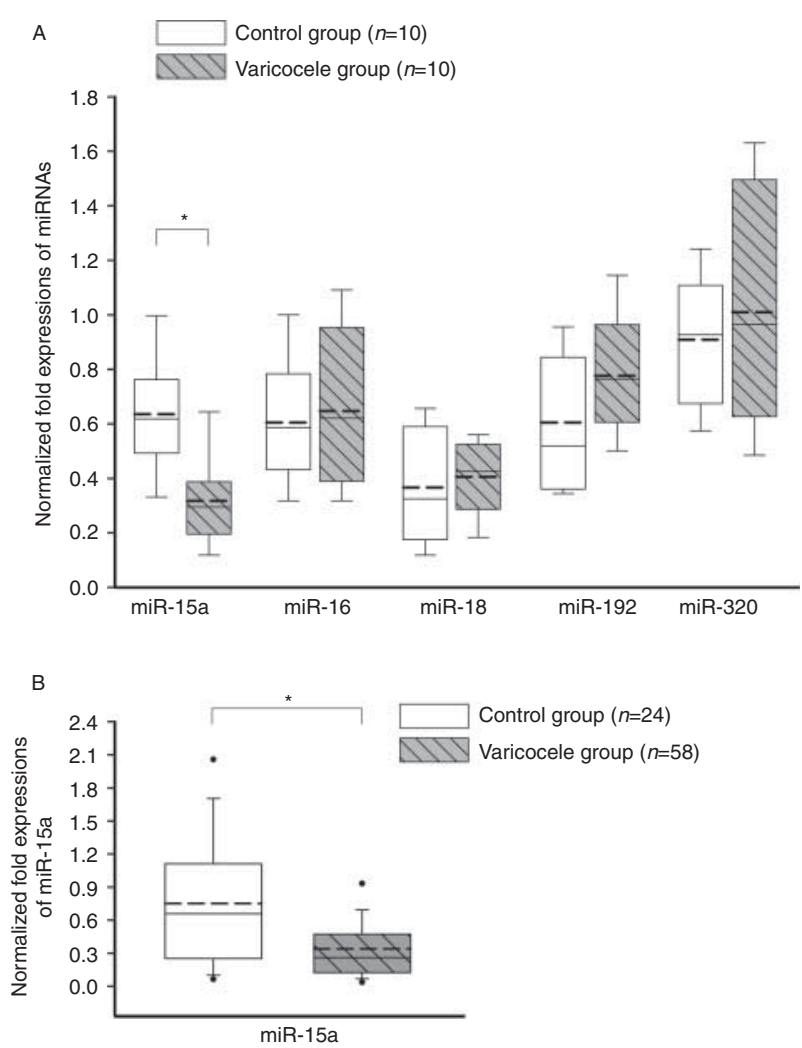

Figure 1 Expressions of miRNAs in the ejaculated spermatozoa. (A) QRT-PCR analysis of the expressions of five miRNAs in the ejaculated spermatozoa of varicocele group or the healthy control. (B) The expression of miR-15a in the ejaculated spermatozoa was significantly decreased in the varicocele group. The expressions of miRNAs in the tested samples were normalized by a calibrator sample from the control group. The horizontal dashed line shows the mean value. ${ }^{*} P<0.05$.

\section{miR-15a directly binds to the 3'-UTR of HSPA1B}

As illustrated in Fig. 3A, alignment of human HSPA1B with miR-15a revealed two putative target sites at positions 45-66 and 83-104 of the HSPA1B 3'-UTR and with an exact match in the seed region at positions 59-65 and 97-103 of the HSPA1B 3'-UTR (Fig. 3A). In order to investigate whether HSPA1B is a target gene of miR-15a, we generated a reporter construct containing the whole 360 nucleotides $3^{\prime}-$ UTR of HSPA1B downstream of the luciferase gene (Fig. 3B). The luciferase reporter construct was co-transfected with $50 \mathrm{nM}$ miR15a mimics or a negative control into HEK 293T cells. The result demonstrated that the luciferase activity was inhibited by miR-15a (Fig. 3C). To further define the miRNA-binding site, two short fragments of HSPA1B $3^{\prime}$-UTR were cloned into the luciferase vector, namely seed 1 and seed 2 respectively. As shown in Fig. 3D and E, the luciferase activity was significantly inhibited by miR$15 \mathrm{a}$ in both seed 1 and seed 2 . Seed 1 had the greater inhibitory effect than seed 2 . Then, we manually changed the potential binding sites by exchanging the $\mathrm{G}$ and $\mathrm{T}$,
A and $C$, which abolished the inhibitory effect of miR$15 \mathrm{a}$ on the luciferase activity (Fig. 3D and E). Given these results, we confirmed HSPA1B as a target gene of miR-15a and identified two binding sites of miR-15a in the 3'-UTR of HSPA1B mRNA.

\section{Expression of HSPA1B in the ejaculated spermatozoa}

The data of qRT-PCR showed that the expression of HSPA $1 B$ mRNA was significantly increased in the sperm of patients with varicocele compared with the control (Fig. 4A). We then collected another ten pairs of sperm samples to perform western blot. As shown in Fig. 4B, the HSPA1B protein was increased in the sperm of patients with varicocele compared with the healthy control. Moreover, the result of Spearman's correlation analysis showed that the expressions of miR-15a and HSPA1B mRNA were significantly correlated. The scatter plot of miR-15a and HSPA1B mRNA expressions was shown in Fig. 4C.

\section{Discussion}

It is well accepted that varicocele can impair spermatogenesis and result in infertility through the induction of hyperthermia and oxidative stresses (Naughton et al. 2001). However, the mechanisms of the stress responses in testis remain to be elucidated. Recently, growing evidence has suggested that stress conditions can alter the biogenesis of miRNAs, the expressions of target mRNAs, and the activities of miRNA-protein complexes (Leung \& Sharp 2010). In turn, several lines of genetic evidence demonstrate that miRNAs play critical roles in the mediation of stress responses (Leung \& Sharp 2007). But whether miRNAs are implicated in varicocelerelated stress environment remains unknown. In this study, we analyzed the expressions of five stress-related miRNAs in the sperm and found that the expression of miR-15a was significantly downregulated in patients with varicocele compared with the control. Furthermore, miR-15a repressed the expression of HSPA1B, which is a typical stress-induced chaperone protein, through directly binding its 3'-UTR. These data show that miRNAs are involved in the regulation of the cellular stress responses in the sperm, and extend our current understanding of varicocele-related infertility.

Since first discovered in 1993, miRNAs have been implicated in various human regulatory pathways, including cell growth, proliferation, apoptosis, and differentiation and therefore participate in the process of development and diseases (He et al. 2009). It has been estimated that miRNAs may regulate up to $30 \%$ of all genes in the human genome (Lewis et al. 2005). The miR-15a/16-1 cluster is located in the host gene DLEU2 at chromosome 13q14.3, a genomic region frequently deleted in B-cell chronic lymphocytic leukemia, myeloma, and mantle cell 

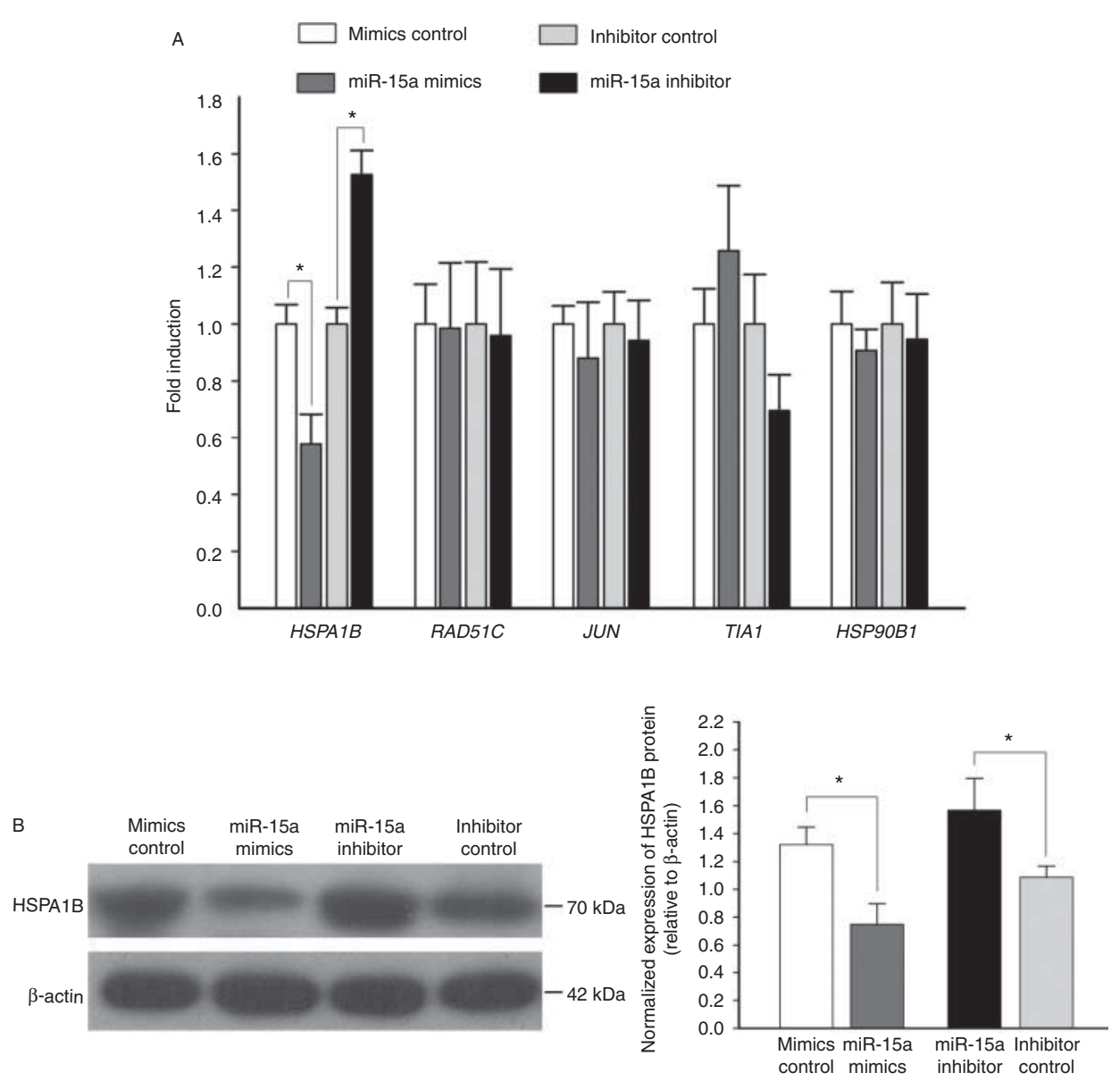

Figure 2 miR-15a-regulated HSPA1B expression. (A) Analysis of the expressions of five putative target genes after miR-15a mimics or inhibitor transfection by qRT-PCR. Human HEK 293T cells were transfected with miR-15a mimics or inhibitor. The concentration of miR-15a mimics and inhibitor was 50 and $100 \mathrm{nM}$ respectively. (B) miR-15a-regulated HSPA1B expression in protein level. The right panel shows the ratios of HSPA1B: $\beta$-actin protein that were quantified by Quantity One Software. Each experiment was performed three times. ${ }^{*} P<0.05$. Error bars indicate S.D.

lymphoma (Lerner et al. 2009). The cluster is highly conserved among mammalian species (Yue \& Tigyi 2010), and these two miRNAs of the cluster are cotranscribed and downregulated in more than two-thirds of chronic lymphocytic leukemia (CLL) patients (Calin et al. 2002, Cimmino et al. 2005). Recently, several studies have demonstrated that miR-15a was involved in the regulation of stress responses. The expression of miR-15a was significantly downregulated in human cells after oxidative stress (Li et al. 2009). The members of miR-15 family act as mediators of stress signaling pathways that regulate cardiomyocyte proliferation and survival in response to stresses (Mendell \& Olson 2012). Inhibition of miR-15 family members provides protection against cardiomyocyte apoptosis after myocardial infarction in rodents (Hullinger et al. 2012). Therefore, the decreased expression of miR-15a in varicocele may protect the sperm from hyperthermia or oxidative stress damage.

In order to find the putative mechanisms, we chose five stress-related genes and only $H S P A 1 B$ was identified as a direct target of miR-15a. The heat-shock proteins
(HSPs), which are regulated by heat-shock factors (HSFs), could stabilize proteins against aggregation and mediate the correct folding of nascent proteins so that the proteins could maintain the precise three-dimensional conformation (Akerfelt et al. 2010). Their expressions are increased when cells are exposed to elevated temperatures or other stresses and thus are crucial for regulation of cellular homeostasis (Tavaria et al. 1996, Katschinski 2004). HSPA1B belongs to HSP70 family and it is one of the most extensively studied heat inducible HSPs (Kampinga et al. 2009, Stetler et al. 2010, Scieglinska et al. 2011). Recent studies have demonstrated that HSF1, HSF2, SP1, and RNA polymerase II are bound to the Hspa1b promoter in the mature spermatozoa of mice, allowing the rapid expression of this cytoprotective gene if the cells encounter stress (Xing etal. 2005, Wilkerson et al. 2008, Wilkerson \& Sarge 2009). In this study, we elucidate the novel post-transcriptional regulation of HSPA1B by miR-15a, extend our knowledge of stress-induced heat-shock response pathway.

Previous studies have shown that HSP70, HSP90, HSPA4, HSF1, and HSF2 were upregulated in the sperm 


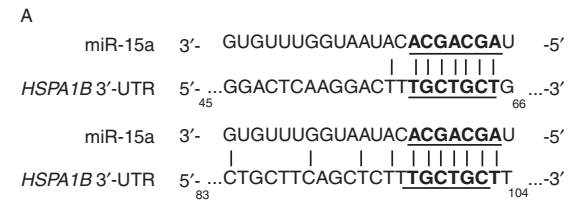

D

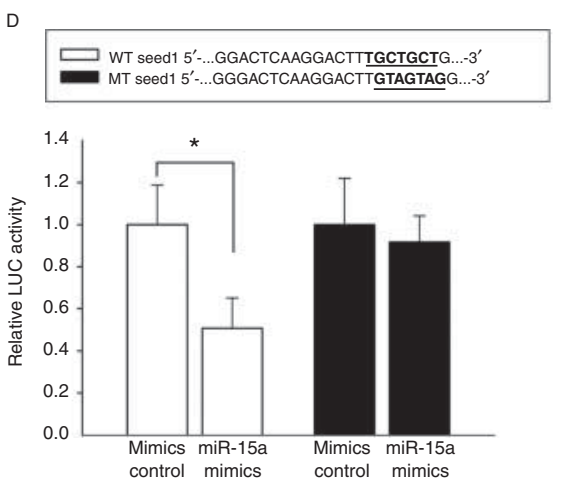

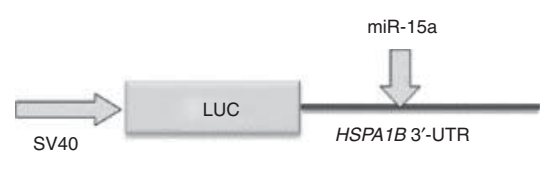

E
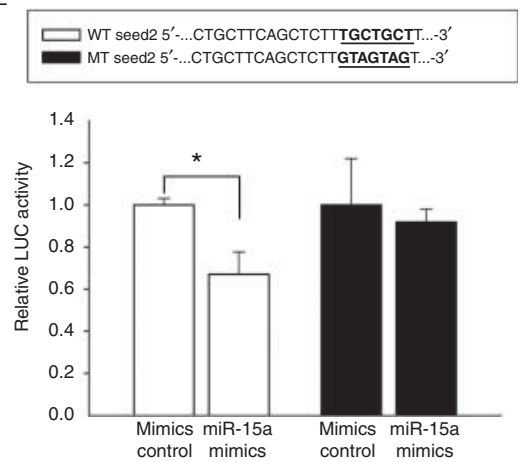

C

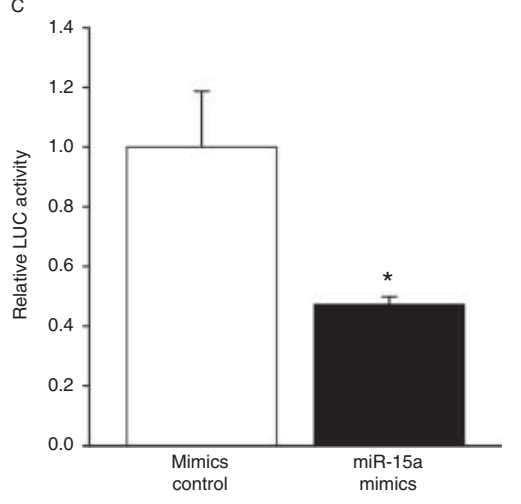

Figure 3 Identification of the miR-15a binding sites. (A) Putative duplex formation of miR-15a and HSPA1B $3^{\prime}-U T R$. There are two putative bindings sites on HSPA1B 3'-UTR. (B) Schematic diagram of luciferase reporter construct. (C) HEK 293T cells were transfected with the reporter together with $50 \mathrm{nM}$ of miR-15a mimics or a negative control and the luciferase reporter assays were performed. (D and E) Two short fragments of $H S P A 1 B 3^{\prime}$-UTR were cloned into the luciferase vector, namely seed 1 and seed 2 respectively. WT sequence containing the putative binding site of miR-15a in bold and underlined. The mutant type (MT) sequence has the altered nucleotides of the binding site. Samples were assayed as in (C). Each experiment was performed three times. ${ }^{*} P<0.05$. Error bars indicate s.D.

of men with varicocele (Ferlin et al. 2010, Chan et al. 2013). Results of our present GRT-PCR analysis are consistent with these studies. HSPA1B plays a crucial role in the promotion of cell survival through refolding of damaged and unfolded proteins generated by stressful stimuli (Jäättelä 1999, Akerfelt et al. 2007) and protects cells against DNA damage (Kotoglou et al. 2009). Moreover, HSPA1B is involved in lightening the damage of hyperthermia on spermatogenesis and post-ejaculatory function of sperm (Meyerhoeffer et al. 1985). It can protect cells from various stresses by inhibiting stress-induced apoptosis. The mechanisms for the anti-apoptosis effect of HSPA1B include inhibiting cytochrome $C$ release from the mitochondria (Li et al. 2000), inhibiting translocation of the Bcl-2 family member Bax (Stankiewicz et al. 2005), preventing the activation of caspase-3 through modulation of the apoptosome (Matsumori et al. 2006), and being the effector of the antiapoptotic Akt/PKB kinase (Barati et al. 2006). Thus, the upregulation of HSPA1B observed in the sperm of varicocele men may be one of the mechanisms that contribute to the protection of hyperthermia or oxidative-induced sperm damage.

Apart from the stress pathway, miR-15a and HSPs are also involved in germ cells development due to their roles in the early stages of spermatogenesis. By targeting cyclin
T2, miR-15a had a negative effect on the early steps of spermatogenesis (Teng et al. 2011). Specifically, HSPs are critically important during spermatogenesis and the posttesticular maturation of mammalian spermatozoa that aberrant expression is associated with spermatogenesis arrested and defects in sperm function (Dun et al. 2012). The stage-specific expression pattern displayed by HSPs during spermatogenesis indicates that HSPs are involved in germ cell development (Feng et al. 2001, Huo et al. 2004, Asquith et al. 2005, Terada et al. 2005, Held et al. 2006, 2011, Adly et al. 2008, Walsh et al. 2008, Lachance et al. 2010, Ji et al. 2012). In addition, HSPA $1 B$ has been implicated in fertilization and embryo development (Neuer et al. 2000, Matwee et al. 2001). It can protect embryos from hyperthermia-induced congenital defects, possibly through reducing hyperthermia-induced apoptosis (Barrier et al. 2009). Taken together, the regulation of $H S P A 1 B$ by miR-15a might play a vital protective role against cellular stresses throughout the processes of spermatozoa maturation, fertilization, and embryo development.

In conclusion, we revealed the altered levels of miR-15a and HSPA $1 B$ in the spermatozoa of varicocele patients and described miR-15a-mediated stress regulation of $H S P A 1 B$ in sperm. Our study may help to better understand the mechanisms involved in 

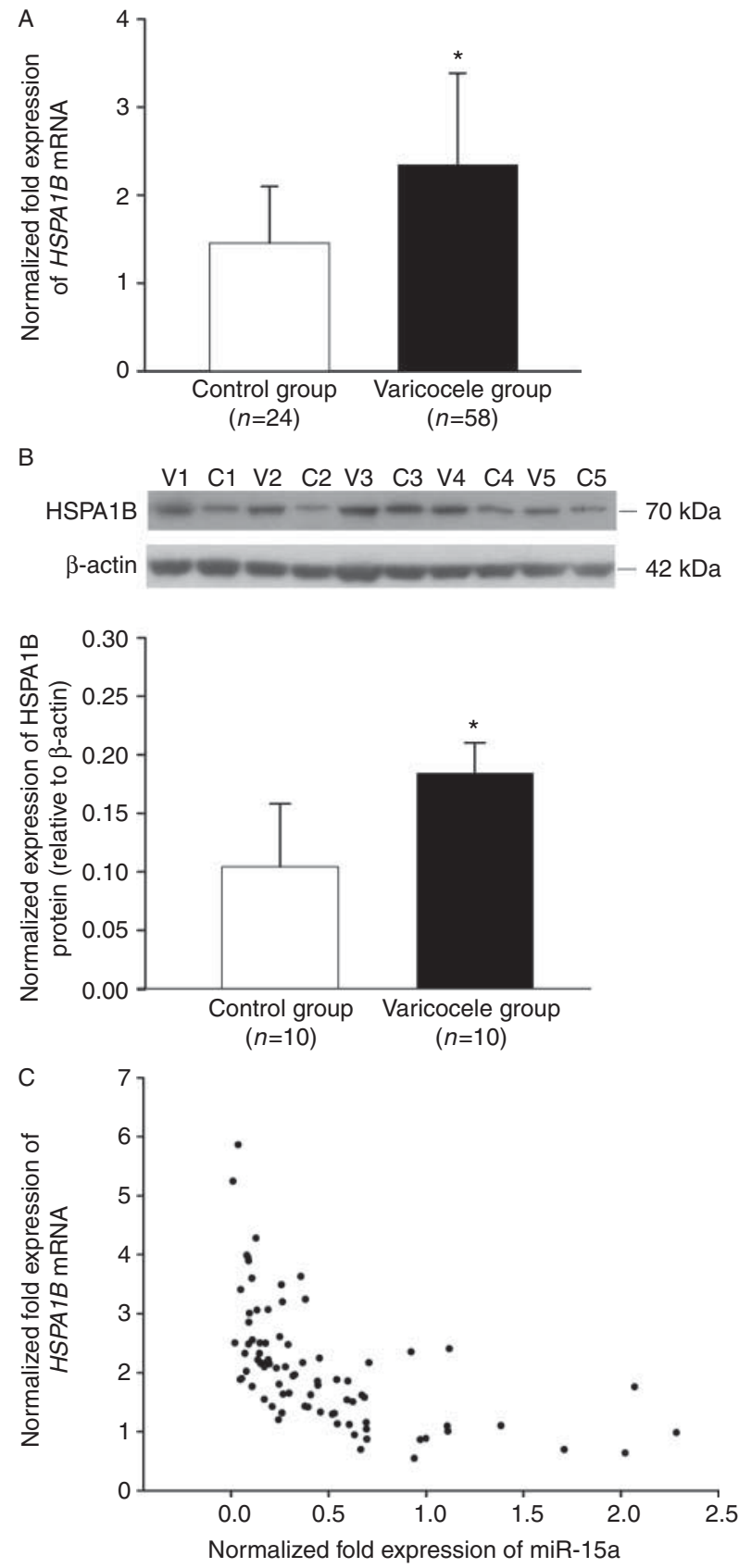

Figure 4 Expression of HSPA1B in the ejaculated spermatozoa. (A) Analysis of the expression of HSPA1B mRNA in the ejaculated spermatozoa of varicocele group or the healthy control by qRT-PCR. The expression of HSPA1B mRNA in the tested samples was normalized by a calibrator sample from the control group. (B) Analysis of the expression of HSPA1B protein in the ejaculated spermatozoa of varicocele group or the healthy control by western blot. Another 20 samples of control group (C1-C10) and varicocele group (V1-V10) were collected and western blotting was carried out. Representative images of ten samples (C1-C5 and $\mathrm{V} 1-\mathrm{V} 5$ ) are shown in the upper panel. The lower panel shows the ratios of HSPA1B: $\beta$-actin protein that were quantified by Quantity One Software. (C) Inverse correlation of miR-15a and HSPA1B mRNA in sperm. The scatter plot of the expressions of miR-15a and HSPA1B mRNA was shown. The correlation coefficient was -0.545 . The expression of miR-15a is listed on the $x$-axis, and the expression of HSPA1B mRNA is listed on $y$-axis. $* P<0$.05. Error bars indicate s.D. varicocele-related sperm damage, and to provide a potential therapeutic target and novel biomarkers for male infertility.

\section{Declaration of interest}

The authors declare that there is no conflict of interest that could be perceived as prejudicing the impartiality of the research reported.

\section{Funding}

This work was supported by the National Key Scientific Program of China (grant number 2011CB944303), the National Natural Science Foundation of China (grant numbers 31271244 and 81200465), and Shenzhen Foundation of Science and Technology (grant numbers CXB201104220045A, 201202001, and 201302053).

\section{Acknowledgements}

The authors thank the patients and the family members for their cooperation during the study.

\section{References}

Abu-Halima M, Hammadeh M, Schmitt J, Leidinger P, Keller A, Meese E \& Backes C 2013 Altered microRNA expression profiles of human spermatozoa in patients with different spermatogenic impairments. Fertility and Sterility 99 1249-1255. (doi:10.1016/j.fertnstert.2012.11. 054)

Adly MA, Assaf HA \& Hussein MR 2008 Heat shock protein 27 expression in the human testis showing normal and abnormal spermatogenesis. Cell Biology International 32 1247-1255. (doi:10.1016/j.cellbi.2008. 07.009)

Akerfelt M, Trouillet D, Mezger V \& Sistonen L 2007 Heat shock factors at a crossroad between stress and development. Annals of the New York Academy of Sciences 1113 15-27. (doi:10.1196/annals.1391.005)

Akerfelt M, Morimoto RI \& Sistonen L 2010 Heat shock factors: integrators of cell stress, development and lifespan. Nature Reviews. Molecular Cell Biology 11 545-555. (doi:10.1038/nrm2938)

Asquith KL, Harman AJ, McLaughlin EA, Nixon B \& Aitken RJ 2005 Localization and significance of molecular chaperones, heat shock protein 1, and tumor rejection antigen gp96 in the male reproductive tract and during capacitation and acrosome reaction. Biology of Reproduction 72 328-337. (doi:10.1095/biolreprod.104.034470)

Barati MT, Rane MJ, Klein JB \& McLeish KR 2006 A proteomic screen identified stress-induced chaperone proteins as targets of Akt phosphorylation in mesangial cells. Journal of Proteome Research $\mathbf{5}$ 1636-1646. (doi:10.1021/pr0502469)

Barrier M, Dix DJ \& Mirkes PE 2009 Inducible 70 kDa heat shock proteins protect embryos from teratogen-induced exencephaly: analysis using Hspa1a/a1b knockout mice. Birth Defects Research. Part A, Clinical and Molecular Teratology 85 732-740. (doi:10.1002/bdra.20610)

Calin GA, Dumitru CD, Shimizu M, Bichi R, Zupo S, Noch E, Aldler H, Rattan S, Keating M \& Rai K 2002 Frequent deletions and downregulation of micro-RNA genes miR15 and miR16 at 13q14 in chronic lymphocytic leukemia. PNAS 99 15524-15529. (doi:10.1073/pnas. 242606799)

Calin GA, Cimmino A, Fabbri M, Ferracin M, Wojcik SE, Shimizu M, Taccioli C, Zanesi N, Garzon R \& Aqeilan RI 2008 MiR-15a and miR-16-1 cluster functions in human leukemia. PNAS 105 5166-5171. (doi:10.1073/pnas.0800121105) 
Chan C-C, Sun G-H, Shui H-A \& Wu G-J 2013 Differential spermatozoal protein expression profiles in men with varicocele compared to control subjects: upregulation of heat shock proteins 70 and 90 in varicocele. Urology 81 1379.e1-1379.e8. (doi:10.1016/j.urology.2013.01.031)

Cimmino A, Calin GA, Fabbri M, lorio MV, Ferracin M, Shimizu M, Wojcik SE, Aqeilan RI, Zupo S \& Dono M 2005 miR-15 and miR-16 induce apoptosis by targeting BCL2. PNAS 102 13944-13949. (doi:10.1073/pnas.0506654102)

Dun MD, Aitken RJ \& Nixon B 2012 The role of molecular chaperones in spermatogenesis and the post-testicular maturation of mammalian spermatozoa. Human Reproduction Update 18 420-435. (doi:10. 1093/humupd/dms009)

Feng HL, Sandlow JI \& Sparks AET 2001 Decreased expression of the heat shock protein hsp70-2 is associated with the pathogenesis of male infertility. Fertility and Sterility 76 1136-1139. (doi:10.1016/S00150282(01)02892-8)

Ferlin A, Speltra E, Patassini C, Pati MA, Garolla A, Caretta N \& Foresta C 2010 Heat shock protein and heat shock factor expression in sperm: relation to oligozoospermia and varicocele. Journal of Urology 183 1248-1252. (doi:10.1016/j.juro.2009.11.009)

Fretz PC \& Sandlow JI 2002 Varicocele: current concepts in pathophysiology, diagnosis, and treatment. Urologic Clinics of North America 29 921-937. (doi:10.1016/S0094-0143(02)00075-7)

Goldstein M \& Eid J 1989 Elevation of intratesticular and scrotal skin surface temperature in men with varicocele. Journal of Urology 142 743-745.

Greenlee AR, Shiao M-S, Snyder E, Buaas FW, Gu T, Stearns TM, Sharma M, Murchison EP, Puente GC \& Braun RE 2012 Deregulated sex chromosome gene expression with male germ cell-specific loss of Dicer1. PLoS ONE 7 e46359. (doi:10.1371/journal.pone.0046359)

Hamada A, Esteves SC \& Agarwal A 2012 Insight into oxidative stress in varicocele-associated male infertility: part 2. Nature Reviews. Urology 10 26-37. (doi:10.1038/nrurol.2012.198)

He Z, Kokkinaki M, Pant D, Gallicano GI \& Dym M 2009 Small RNA molecules in the regulation of spermatogenesis. Reproduction 137 901-911. (doi:10.1530/REP-08-0494)

Held T, Paprotta I, Khulan J, Hemmerlein B, Binder L, Wolf S, Schubert S, Meinhardt A, Engel W \& Adham IM 2006 Hspa4l-deficient mice display increased incidence of male infertility and hydronephrosis development. Molecular and Cellular Biology 26 8099-8108. (doi:10.1128/MCB. 01332-06)

Held T, Barakat AZ, Mohamed BA, Paprotta I, Meinhardt A, Engel W \& Adham IM 2011 Heat-shock protein HSPA4 is required for progression of spermatogenesis. Reproduction 142 133-144. (doi:10.1530/REP-11-0023)

Hullinger TG, Montgomery RL, Seto AG, Dickinson BA, Semus HM, Lynch JM, Dalby CM, Robinson K, Stack C \& Latimer PA 2012 Inhibition of miR-15 protects against cardiac ischemic injury. Circulation Research 110 71-81. (doi:10.1161/CIRCRESAHA.111.244442)

Huo R, Zhu YF, Ma X, Lin M, Zhou ZM \& Sha JH 2004 Differential expression of glucose-regulated protein 78 during spermatogenesis. Cell and Tissue Research 316 359-367. (doi:10.1007/s00441-004-0885-7)

Inui M, Martello G \& Piccolo S 2010 MicroRNA control of signal transduction. Nature Reviews. Molecular Cell Biology 11 252-263. (doi:10.1038/nrm2868)

Jäättelä M 1999 Heat shock proteins as cellular lifeguards. Annals of Medicine 31 261-271. (doi:10.3109/07853899908995889)

Ji Z-L, Duan Y-G, Mou L-S, Allam J-P, Haidl G \& Cai Z-M 2012 Association of heat shock proteins, heat shock factors and male infertility. Asian Pacific Journal of Reproduction 1 76-84. (doi:10.1016/S2305-0500(13)60053-6)

Jung A \& Schuppe HC 2007 Influence of genital heat stress on semen quality in humans. Andrologia 39 203-215. (doi:10.1111/j.1439-0272.2007. 00794.x)

Kampinga HH, Hageman J, Vos MJ, Kubota H, Tanguay RM, Bruford EA, Cheetham ME, Chen B \& Hightower LE 2009 Guidelines for the nomenclature of the human heat shock proteins. Cell Stress \& Chaperones 14 105-111. (doi:10.1007/s12192-008-0068-7)

Katschinski DM 2004 On heat and cells and proteins. Physiology 19 11-15. (doi:10.1152/nips.01403.2002)

Kedersha N, Cho MR, Li W, Yacono PW, Chen S, Gilks N, Golan DE \& Anderson P 2000 Dynamic shuttling of TIA-1 accompanies the recruitment of mRNA to mammalian stress granules. Journal of Cell Biology 151 1257-1268. (doi:10.1083/jcb.151.6.1257)
Korhonen HM, Meikar O, Yadav RP, Papaioannou MD, Romero Y, Da Ros M, Herrera PL, Toppari J, Nef S \& Kotaja N 2011 Dicer is required for haploid male germ cell differentiation in mice. PLOS ONE 6 e24821. (doi:10.1371/journal.pone.0024821)

Kotoglou P, Kalaitzakis A, Vezyraki P, Tzavaras T, Michalis LK, Dantzer F, Jung JU \& Angelidis C $2009 \mathrm{Hsp70}$ translocates to the nuclei and nucleoli, binds to XRCC1 and PARP-1, and protects HeLa cells from single-strand DNA breaks. Cell Stress \& Chaperones 14 391-406. (doi:10.1007/s12192-008-0093-6)

Kyriakis JM, Banerjee P, Nikolakaki E, Dai T, Rubie EA, Ahmad MF, Avruch J \& Woodgett JR 1994 The stress-activated protein kinase subfamily of c-Jun kinases. Nature 369 156-160. (doi:10.1038/369156a0)

Lachance C, Fortier M, Thimon V, Sullivan R, Bailey JL \& Leclerc P 2010 Localization of Hsp60 and Grp78 in the human testis, epididymis and mature spermatozoa. International Journal of Andrology 33 33-44. (doi:10. 1111/j.1365-2605.2008.009REF38=10.1016/j.molcel.2010.09.027)

Landgraf P, Rusu M, Sheridan R, Sewer A, lovino N, Aravin A, Pfeffer S, Rice A, Kamphorst AO \& Landthaler M 2007 A mammalian microRNA expression atlas based on small RNA library sequencing. Cell 129 1401-1414. (doi:10.1016/j.cell.2007.04.040)

Lerner M, Harada M, Lovén J, Castro J, Davis Z, Oscier D, Henriksson M, Sangfelt O, Grandér D \& Corcoran MM 2009 DLEU2, frequently deleted in malignancy, functions as a critical host gene of the cell cycle inhibitory microRNAs miR-15a and miR-16-1. Experimental Cell Research 315 2941. (doi:10.1016/j.yexcr.2009.07.001)

Leung AK \& Sharp PA 2007 microRNAs: a safeguard against turmoil? Cell 130 581-585. (doi:10.1016/j.cell.2007.08.010)

Leung AK \& Sharp PA 2010 MicroRNA functions in stress responses. Molecular Cell 40 205-215. (doi:10.1016/j.molcel.2010.09.027)

Lewis BP, Burge CB \& Bartel DP 2005 Conserved seed pairing, often flanked by adenosines, indicates that thousands of human genes are microRNA targets. Cell 120 15-20. (doi:10.1016/j.cell.2004.12.035)

Li C-Y, Lee J-S, Ko Y-G, Kim J-I \& Seo J-S 2000 Heat shock protein 70 inhibits apoptosis downstream of cytochrome $c$ release and upstream of caspase-3 activation. Journal of Biological Chemistry 275 25665-25671. (doi:10.1074/jbc.M906383199)

Li G, Luna C, Qiu J, Epstein DL \& Gonzalez P 2009 Alterations in microRNA expression in stress-induced cellular senescence. Mechanisms of Development 130 731-741. (doi:10.1016/j.mad.2009.09.002)

Lian J, Zhang X, Tian H, Liang N, Wang Y, Liang C, Li X \& Sun F 2009 Altered microRNA expression in patients with non-obstructive azoospermia. Reproductive Biology and Endocrinology 7 13. (doi:10.1186/ 1477-7827-7-13)

Maki RG, Old LJ \& Srivastava PK 1990 Human homologue of murine tumor rejection antigen gp96: $5^{\prime}$-regulatory and coding regions and relationship to stress-induced proteins. PNAS 87 5658-5662. (doi:10.1073/pnas. 87.15.5658)

Matsumori Y, Northington FJ, Hong SM, Kayama T, Sheldon RA, Vexler ZS, Ferriero DM, Weinstein PR \& Liu J 2006 Reduction of caspase-8 and -9 cleavage is associated with increased c-FLIP and increased binding of Apaf-1 and Hsp70 after neonatal hypoxic/ischemic injury in mice overexpressing Hsp70. Stroke 37 507-512. (doi:10.1161/01.STR. 0000199057.00365.20)

Matwee C, Kamaruddin M, Betts DH, Basrur P \& King WA 2001 The effects of antibodies to heat shock protein 70 in fertilization and embryo development. Molecular Human Reproduction 7 829-837. (doi:10.1093/molehr/7.9.829) (doi:10.1093/molehr/7.9.829)

Mendell JT \& Olson EN 2012 MicroRNAs in stress signaling and human disease. Cell 148 1172-1187. (doi:10.1016/j.cell.2012.02.005)

Meyerhoeffer D, Wettemann R, Coleman S \& Wells M 1985 Reproductive criteria of beef bulls during and after exposure to increased ambient temperature. Journal of Animal Science $\mathbf{6 0} 352$.

Mostafa T, Anis T, Imam H, El-Nashar A \& Osman I 2009 Seminal reactive oxygen species-antioxidant relationship in fertile males with and without varicocele. Andrologia 41 125-129. (doi:10.1111/j.1439-0272.2008. 00900.x)

Naughton CK, Nangia AK \& Agarwal A 2001 Varicocele and male infertility: part II. Pathophysiology of varicoceles in male infertility. Human Reproduction Update 7 473-481. (doi:10.1093/humupd/7.5.473)

Neuer A, Spandorfer S, Giraldo P, Dieterle S, Rosenwaks Z \& Witkin S 2000 The role of heat shock proteins in reproduction. Human Reproduction Update 6 149-159. (doi:10.1093/humupd/6.2.149) 
Qian S-B, McDonough H, Boellmann F, Cyr DM \& Patterson C 2006 CHIP-mediated stress recovery by sequential ubiquitination of substrates and Hsp70. Nature 440 551-555. (doi:10.1038/nature04600)

Ren X-P, Wu J, Wang X, Sartor MA, Qian J, Jones K, Nicolaou P, Pritchard TJ \& Fan G-C 2009 MicroRNA-320 is involved in the regulation of cardiac ischemia/reperfusion injury by targeting heat-shock protein 20 . Circulation 119 2357-2366. (doi:10.1161/CIRCULATIONAHA.108. 814145)

Ro S, Park C, Sanders KM, McCarrey JR \& Yan W 2007 Cloning and expression profiling of testis-expressed microRNAs. Developmental Biology 311 592-602. (doi:10.1016/j.ydbio.2007.09.009)

Romero Y, Meikar O, Papaioannou MD, Conne B, Grey C, Weier M, Pralong F, De Massy B, Kaessmann H \& Vassalli J-D 2011 Dicer1 depletion in male germ cells leads to infertility due to cumulative meiotic and spermiogenic defects. PLoS ONE 6 e25241. (doi:10.1371/journal. pone.0025241)

Sage JM, Gildemeister OS \& Knight KL 2010 Discovery of a novel function for human Rad51 maintenance of the mitochondrial genome. Journal of Biological Chemistry 285 18984-18990. (doi:10.1074/jbc. M109.099846)

Scieglinska D, Piglowski W, Chekan M, Mazurek A \& Krawczyk Z 2011 Differential expression of HSPA1 and HSPA2 proteins in human tissues; tissue microarray-based immunohistochemical study. Histochemistry and Cell Biology 135 337-350. (doi:10.1007/s00418-011-0791-5)

Smith R, Kaune H, Parodi D, Madariaga M, Ríos R, Morales I \& Castro A 2006 Increased sperm DNA damage in patients with varicocele: relationship with seminal oxidative stress. Human Reproduction 21 986-993. (doi:10.1093/humrep/dei429)

Stankiewicz AR, Lachapelle G, Foo CP, Radicioni SM \& Mosser DD 2005 Hsp70 inhibits heat-induced apoptosis upstream of mitochondria by preventing Bax translocation. Journal of Biological Chemistry 280 38729-38739. (doi:10.1074/jbc.M509497200)

Stetler RA, Gan Y, Zhang W, Liou AK, Gao Y, Cao G \& Chen J 2010 Heat shock proteins: cellular and molecular mechanisms in the central nervous system. Progress in Neurobiology 92 184-211. (doi:10.1016/ j.pneurobio.2010.05.002)

Tavaria M, Gabriele T, Kola I \& Anderson RL 1996 A hitchhiker's guide to the human Hsp70 family. Cell Stress \& Chaperones 1 23. (doi:10.1379/ 1466-1268(1996)001 <0023:AHSGTT>2.3.CO;2)

Teng Y, Wang Y, Fu J, Cheng X, Miao S \& Wang L 2011 Cyclin T2: a novel miR-15a target gene involved in early spermatogenesis. FEBS Letters 585 2493-2500. (doi:10.1016/j.febslet.2011.06.031)
Terada K, Yomogida K, Imai T, Kiyonari H, Takeda N, Kadomatsu T, Yano M, Aizawa S \& Mori M 2005 A type I Dnal homolog, DjA1, regulates androgen receptor signaling and spermatogenesis. EMBO Journal 24 611-622. (doi:10.1038/sj.emboj.7600549)

Twigg J, Fulton N, Gomez E, Irvine DS \& Aitken RJ 1998 Analysis of the impact of intracellular reactive oxygen species generation on the structural and functional integrity of human spermatozoa: lipid peroxidation, DNA fragmentation and effectiveness of antioxidants. Human Reproduction 13 1429-1436. (doi:10.1093/humrep/13.6.1429)

Walsh A, Whelan D, Bielanowicz A, Skinner B, Aitken RJ, O'Bryan MK \& Nixon B 2008 Identification of the molecular chaperone, heat shock protein 1 (chaperonin 10), in the reproductive tract and in capacitating spermatozoa in the male mouse. Biology of Reproduction 78 983-993. (doi:10.1095/biolreprod.107.066860)

Wilkerson DC \& Sarge KD 2009 RNA polymerase II interacts with the Hspa1b promoter in mouse epididymal spermatozoa. Reproduction 137 923-929. (doi:10.1530/REP-09-0015)

Wilkerson DC, Murphy LA \& Sarge KD 2008 Interaction of HSF1 and HSF2 with the Hspa1b promoter in mouse epididymal spermatozoa. Biology of Reproduction 79 283-288. (doi:10.1095/biolreprod.107.066241)

Will MA, Swain J, Fode M, Sonksen J, Christman GM \& OhI D 2011 The great debate: varicocele treatment and impact on fertility. Fertility and Sterility 95 841-852. (doi:10.1016/j.fertnstert.2011.01.002)

Wilmink GJ, Roth CL, Ibey BL, Ketchum N, Bernhard J, Cerna CZ \& Roach WP 2010 Identification of microRNAs associated with hyperthermia-induced cellular stress response. Cell Stress \& Chaperones 15 1027-1038. (doi:10.1007/s12192-010-0189-7)

World Health Organization 2010 In WHO Laboratory Manual for the Examination and Processing of Human Semen, 5th edn. Geneva, Switzerland: World Health Organization, WHO Press.

Xing H, Wilkerson DC, Mayhew CN, Lubert EJ, Skaggs HS, Goodson ML, Hong Y, Park-Sarge O-K \& Sarge KD 2005 Mechanism of hsp70i gene bookmarking. Science 307 421-423. (doi:10.1126/science.1106478)

Yue J \& Tigyi G 2010 Conservation of miR-15a/16-1 and miR-15b/16-2 clusters. Mammalian Genome 21 88-94. (doi:10.1007/s00335-0099240-3)

Received 16 December 2013

First decision 8 January 2014

Revised manuscript received 24 January 2014

Accepted 30 January 2014 